\title{
El prurito del perito
}

\section{Francisco González de Cossío}

En las disputas complejas, incluyendo las de construcción, los expertos juegan un papel clave. El contenido y alcance preciso del mismo es, sin embargo, malentendido en lo conceptual y mal implementado en la praxis. Como resultado, con frecuencia, la participación de expertos dista de ser lo que podría - y debería - ser. En los casos en los que la pericia es un insumo necesario, la consecuencia de lo descrito oscila entre desperdicio y oportunidades perdidas, hasta desastre. Decisiones divorciadas $-\mathrm{y}$, con frecuencia, erróneas - de la ciencia técnica sobre las que versan.

El escenario puede parecer pesimista; melodramático, incluso. Sin embargo, no es irrealista. A continuación se expondrá el origen del problema (punto 1), para luego ofrecer una solución (punto 2).

\section{Malentendido}

Se observan diferentes formas de entender el papel del perito. Por ejemplo, hay quien entiende al perito como un aliado del equipo que representa a la parte en el proceso, cuya lealtad expositiva se debe a quien lo nombró. Como resultado, todo lo que el perito dice, hace y omite tiene una finalidad: defender. Exponer el punto técnico de la manera que más asiste a quien lo ofrece (en verdad, su cliente). 
Existe otra visión, sin embargo. Hay quien entiende al perito como una persona que debe ilustrar, no abogar. Debe trasmitir las normas de la ciencia en la cual es experto al tomador de decisión (juez o árbitro). Ello debe incluir la traducción del lenguaje técnico al común y corriente para que sea entendido por el juzgador - en sí, un experto en otra materia (la jurídica).

Esta concepción, con seguridad, atraerá comentarios diversos. Desde crítica hasta matices, incluyendo quien la considere inocente, señalando la práctica cotidiana como evidencia de ello. Y es de admitirse que el crítico encontraría más apoyo del que nos gustaría admitir. Aunque el señalamiento, es de admitirse, sería correcto (por lo menos en un número importante de casos), ello no quiere decir que no haya una mejor manera de hacer las cosas. Un ideal que perseguir. Y dicho ideal tiene implicaciones pragmáticas importantes. Las comentaré (punto 1.2), no sin antes aludir a los síntomas visibles en la postura contraria (punto 1.1).

\subsection{Síntomas}

El problema descrito tiene síntomas que, con probabilidad, el lector experimentado ha vivido. Por ejemplo:

1) Es raro encontrar un perito que difiera de la parte que lo nombra. Es cierto que esto podría ${ }^{1}$ explicarse por el hecho de que un abogado no va a presentar una pericial que no sirva a su causa. Luego, entonces, si hizo su trabajo bien, la opinión elegida será consistente con la postura defendida. Pero el hecho también puede ser comunicativo de algo diverso: que el perito esté presto a decir lo que se le pida - al margen de lo que su ciencia diga al respecto.

2) El contenido de la pericial tiende a ser argumentativo. Ello es in natura diverso a lo que un perito debe hacer. Un perito debe ilustrar, no abogar; para eso están los abogados.

3) En la examinación cruzada durante la audiencia, frecuentemente se observa que los peritos son gelatinosos en su actuar. En ocasiones, lejos de contestar, buscan evadir. Ello es comunicativo. Su comportamiento es parecido al de un pez que desea escaparse de las redes cuando es pescado - algo muy distinto a dar una contestación sincera.

1 El que así sea es casuista. 
Como puede observarse, se advierte una marcada diferencia de práctica sobre lo que se dice que es el papel del perito y lo que se hace. Y, como dice el dicho: "El árbol se ve por sus frutos".

\subsection{Consecuencias}

Bajo la aproximación que critico, algo se pierde. Si se acepta como regla, el resultado será que el juzgador siempre tiene una visión parcial y sesgada del componente técnico de la disputa. Y, en ausencia de mecanismos correctores ${ }^{2}$, sus opciones al juzgar oscilarán entre tener que tomar una decisión con información subóptima, hasta verse obligado a escoger de entre dos polos el menos extremo o irracional. Siendo que no habla el idioma - no es experto en la materia cuya exposición está en vías de analizar-, es justificado suponer que su apreciación será imperfecta, ya sea en la mayoría de los casos o siempre. Resultado: en el mejor de los casos, decisiones basadas en tierra movediza conceptual. En el peor $-\mathrm{y}$ más probable-: fallos erróneos. Y cuando el hecho técnico a ser determinado sea lo que actualice la hipótesis normativa de la cual se derivarán consecuencias legales, el yerro propiciado por el fenómeno denunciado bien puede afectar la rectitud del laudo en su totalidad.

Como puede verse, la práctica que cuestiono es peligrosa. Puede demeritar el núcleo de la decisión o aspectos importantes de ella ${ }^{3}$. Es

2 Como la designación de un perito experto tercero en discordia, que el tribunal cuente con 'su' perito, o que el árbitro motu proprio examine directamente, entre otros. Sin embargo, los mecanismos correctores pueden ser de difícil o infrecuente utilización. Lo que es más, pueden generar otros problemas (que no abordo). Siendo que lo que se busca es resolver un problema que podría evitarse, dichas (lamentables y difíciles de corregir) consecuencias son motivos adicionales para seguir la postura por la que aquí se aboga.

3 En una obra reciente, un pensador importante (Posner, 2013) comenta los retos que la 'complejidad' y 'dificultad' (conceptos que distingue (id., pp. 3 y 54 et seq)) imponen a quienes se dedican a juzgar, así como su preocupación sobre cómo dichos retos son enfrentados por el juzgador. Sus reflexiones y advertencias son relevantes y merecen eco en este ensayo, pues la respuesta del derecho procesal a dicho reto es la figura del 'perito'. La falta de claridad sobre cómo usar dicha figura hará que los retos que la (crecientemente compleja) labor del juzgador (judicial y arbitral) vive sean manejados en forma que dista de ser la óptima. Proviniendo de una persona tan experimentada y reflectiva - además de reconoci$\mathrm{da}-$, sus advertencias son dignas de consideración para quienes nos dedicamos al arbitraje. 
por ello que se propone revisitarla. La postura "inocente" merece ser defendida puesto que incrementa la calidad del sistema, así como la percepción ética del mismo. Ambos motivos son individualmente suficientes para defender el postulado. El que una forma de usar una herramienta procesal sea per se más conducente a la calidad del sistema in toto, es motivo suficiente para apoyarlo. Pero, además, el que incremente la percepción de que el sistema es mejor -más limpio-, es en sí un motivo independientemente suficiente para defenderlo.

\section{El papel del perito}

\subsection{El ideal}

El perito debe ilustrar. Orientar. Influir en el componente técnico de la decisión que tome el árbitro. Para ello, debe comunicarse con profundidad y con sinceridad con el juzgador sobre los puntos técnicos evocados por la litis que está en vías de juzgar.

Cuando un aspecto de la disputa es técnico, no es exageración decir que el árbitro (que no conoce la ciencia relevante y necesaria para aquilatar el aspecto técnico de su decisión) está en manos del perito. Si el perito informa bien, es más probable que el fallo salga bien. Y lo inverso es igualmente cierto.

\subsection{Dificultad}

Es raro observar que el perito se desempeñe en la forma sugerida ${ }^{4}$; pero en los casos en que ha ocurrido, el resultado ha sido muy positivo. Por ende, vale la pena entender el motivo de la infrecuencia a efectos de fomentar el resultado.

Sospecho que la infrecuencia obedece a un doble factor. Primero, el estatus actual de la praxis es tal que la estrategia dominante al escoger un perito tiende a ser contraria al ideal aquí defendido. Proponer a un perito 'inocente' puede ${ }^{5}$ implicar una desventaja procesal - pues lo más probable es que la otra parte proponga un perito 'dúctil' - . Y ello deto-

4 Y cuando ocurre, dada la praxis descrita, existe un manto de sospecha sobre él, tanto de los juzgadores (jueces y árbitros) como contrapartes.

5 Digo 'puede', pues el resultado no es obligado. Si el árbitro es sofisticado, proponer a un perito 'inocente' será una ventaja. Primero, porque será más persuasivo. Segundo, por lo que comunica: que la parte juega limpio. 
na una espiral negativa: partes deseosas de hacer un uso correcto del instrumento pericial pueden verse orilladas a 'jugar sucio' (escoger un perito maleable) para cerciorarse de que contrarrestan a su adversario. Hacer lo contrario ('jugar limpio') puede sentirse inconveniente por inocente. Segundo, dada la práctica actual, existirá un manto de sospecha sobre el experto propuesto por una parte ${ }^{6}$. Por ende, es posible que hayan existido casos de peritos correctos, 'inocentes', que hayan pasado desapercibidos.

Experiencias recientes me hacen pensar que este factor puede ser mucho más frecuente de lo que nos damos cuenta. En un caso reciente e importante, la energía con la que los representantes de una parte hacían ataques ad hominem al perito - y no solo en el contexto del asunto, sino en foros académicos y tras bambalinas - , es evidencia de que estaban convencidos de que el perito actuaba con sesgo, no obstante que no era el caso ${ }^{7}$. Y cuando alguien está convencido de algo, la evidencia en contra se descuenta - consciente o inconscientemente.

En el caso que tengo en mente, el perito hizo esfuerzos significativos para hablar con franqueza y expresar una opinión objetiva ${ }^{8}$. En respuesta, tanto el perito contrario como los abogados que lo presentaron se dedicaban a atacarlo en lo personal, más que a refutar su dictamen. Al hacerlo, inter alia, se intentaba insinuar contradicción entre lo que explicaba en su dictamen y sus escritos académicos ${ }^{9}$. Lo ocurrido puede parecer normal: se trata de una táctica frecuente y aceptada tanto en

6 Esta sospecha genera una predisposición que puede no solo ser fuerte y difícil de vencer, sino peligrosa al propiciar errores al juzgar. Estando acostumbrado a la praxis cuestionable, un árbitro puede pasar por alto una pericial sincera dada la frecuencia con la que ha visto periciales cuestionables.

7 Explicar por qué esto es cierto sería arduo y exigiría entrar al fondo del caso - algo indisponible por confidencialidad, e impráctico dada la complejidad-. Sin embargo, puede generalizarse que sus dictámenes eran cuidadosamente elaborados para no decir nada que no fuera totalmente objetivo. Eran expositivos, no argumentativos.

8 Lo cual sitúa a peritos en una situación difícil. La parte que lo ofrece hará esfuerzos para que presente su opinión de la manera que más le conviene. Si se niega - como ocurrió en este caso-, el resultado puede ser que no satisface a nadie: ni a quien lo presenta, ni al juzgador $-\mathrm{y}$ obviamente no a la parte contraria.

9 El ejercicio - de sí aceptable - era realizado en forma sesgada, mal citando (con frecuencia fuera de contexto y poniendo palabras en su boca). Y los adjetivos y ataques personales eran tan frecuentes como estridentes. 
proceso (arbitral y otro) nacional e internacional. Mi punto no es mostrar extrañeza con la táctica, sino cómo, aun en casos en que el experto se esmera por ser sincero y no sesgado, es visto con sospecha y atacado. Ello es resultado de lo acendrado de la praxis actual. En el caso que aludo, llamaba la atención el (enorme) esfuerzo que el perito hizo para hablar con franqueza, incluso admitiendo debilidades de $s u$ dictamen (a la luz de la materia de su pericia) cuando fue preguntado.

He ponderado sobre dicho incidente y tiendo a pensar que lo ocurrido se explica por el mecanismo de defensa llamado "proyección": vemos en otros los defectos que encarnamos. Es decir, el dicho bíblico: "Ves la paja en el ojo de tu hermano y no la viga que llevas en el tuyo"10, tiene raíces psicológicas defensivas.

Al margen del resultado propiciado por el fenómeno psicológico, y dejando de lado la descortesía profesional (a veces personal), esta forma de argumentar pierde algo. Ese algo es elocuentemente expuesto por Mario Vargas Llosa en su ensayo las "Reglas del juego":

[...] Parece casi fatídico que las polémicas, entre nosotros, al margen de los asuntos que los motiven, se reduzcan tarde o temprano a tratar de descalificar moralmente al adversario. Más importante que rebatir sus ideas es sumirlo en la ignominia, aunque sea con golpes bajos como el insulto y la calumnia. Estos métodos pierden a quien los emplea en los países cultos, aquellos en los que se considera que el juego es tan importante como las reglas del juego. En los nuestros, no. Quien degüella al adversario, también ganó la discusión y se le llama, con justicia, "temible polemista". [...] Todo esto tiene un lado triste, porque simboliza nuestro atraso. Pero también es cómico, chispeante, vital [...] (2009, pp. 183-184).

La crítica de Vargas Llosa no solo es atinada; es ubicua y conspicua. Lo que es más, contiene el mensaje que se desea trasmitir en este ensayo: el prurito del perito debe ser comprender que tan importante como el resultado del juego es seguir las reglas del juego ${ }^{11}$.

Nunca dejaré de impresionarme por la frecuencia con la que quienes más incurren en la praxis criticable, se la reprochan a otros - con fre-

10 Lucas 6, 39-42.

11 Esta apreciación tiene ramificaciones profundas. Cuando las reglas se respetan, el resultado del proceso no solo es legítimo, se siente legítimo. Y lo inverso es igualmente cierto. 
cuencia, sin mérito- ${ }^{12}$. Como indiqué, sospecho que ello es un caso freudiano de proyección -incluso transferencia - como mecanismo de defensa. Pero cualquiera que sea el motivo, el punto merece atención por los motivos señalados por Vargas Llosa: nos arrastran a niveles bajos de discusión. De hecho, mi única diferencia con respecto a la (dura, pero aguda) crítica de Vargas Llosa es que el panorama visible sea cómico. Dista de serlo. El motivo: su consecuencia. Como resultado de la práctica que cuestiono, se priva al proceso de un insumo importante: pericia inteligentemente expuesta. Como resultado, el fallo sufre. Dista de ser lo que podría ser.

Por ende, no obstante la dificultad, vale la pena defender la práctica aplaudida. Los motivos son los descritos: la mejora de la calidad del sistema de solución de controversias y su percepción - dos fines independientemente suficientes para dar el paso defendido-. Como diría Vargas Llosa: es tan importante el juego como las reglas del juego. Esto debe ser el prurito del perito.

\subsection{Una sutileza: defendiendo sin abogar}

La postura encomiada no es incompatible con defender, siempre que verse sobre lo correcto y se haga de la forma correcta. Me explico.

Un perito puede defender, siempre que la defensa verse sobre su opinión, no la parte o su postura en proceso. Además, hay un cauce apropiado para ello. Ello es legítimo si constituye la opción que merece la aprobación o preferencia dentro de las opciones posibles bajo los cánones de la ciencia en la cual se especializa. Lo que no es correcto es falsear. Sobre o subexponer. Aprovechar la ignorancia del árbitro para exponer una postura falsa, o como si fuera la única, o como si las opciones fueran tan improcedentes que no merecen ser aludidas - convenientemente, aquellas que no sirven al caso de quien lo designó (su cliente).

Esto último es importante, pues existen periciales que refugian sesgo bajo el argumento de que es su opinión. Dado que es difícil discernir, por esta ranura se cuela actividad indeseable. Para distinguir, propondría que la estrella polar del actuar debe ser que la opinión que el perito

12 Por cierto, la aseveración no solo aplica a los peritos, también a los árbitros. En los casos que he compartido tribunal arbitral con árbitros parciales, me he percatado que son los parciales los que sospechan parcialidad de los demás. Y lo inverso es igualmente cierto. 
tenga y presente debe resistir análisis bajo los cánones de la ciencia en que se presenta. Es decir, bajo el manto de "mi opinión" no se puede decir lo que sea.

Esto último detona un dilema. Como es sabido, mucho del crecimiento y mejoría del conocimiento se le debe a los pensadores que cuestionaron un paradigma y tuvieron el valor de sostener una postura minoritaria hasta que, pasado el tiempo y después de sujetarlo a la dialéctica, se hizo mainstream. Es decir, es mediante el debate que la minoría a veces se torna en mayoría. Esto no solo es un proceso interesante, sino bello. Y el progreso depende de ello" ${ }^{13}$. Es decir, existe un "mercado de las ideas"14: nuevas ideas son presentadas a los consumidores de las ideas (los pensadores, incluyendo los expertos en una ciencia), quienes, después de consumirlas, las aceptan o rechazan dependiendo de si la idea constituye una aportación a la ciencia en cuestión. Visto así, para que dicho 'mercado' sea 'eficiente' se requiere de tolerancia. Apertura intelectual. Deshacernos de dogmatismo. Entender que el acervo actual de conocimiento es poroso; admite nuevas ideas. Y que ello es sano.

El proceso descrito genera una tensión que guarda relevancia con nuestro tema. Siendo aceptado que se vale tener opiniones distintas a mainstream, por un lado, pero aceptado también que bajo el argumento 'mi opinión' no puede decirse lo que sea, ¿cómo distinguir? ¿Cómo discernir entre opiniones frescas que merecen ser toleradas mientras son escudriñadas, pero son contrarias a lo más aceptado dentro de la ciencia en cuestión, de la paja -incluyendo ipse dixit de pistoleros a sueldo que se dicen 'expertos'?

Contestaría que una apreciación - aunque minoritaria - debe ser ofrecida por un experto si sigue y satisface los métodos aceptados por la ciencia en la cual es perito. Cualquier otra cosa sería inservible por inaceptable. Por ser producto intelectual que no pasa escrutinio de método científico. Paja.

Cuando el perito hace lo anterior, algo interesante -incluso bello ${ }^{15}$ sucede. El juzgador es puesto en sintonía con el dilema que suscita la cuestión por resolver. $\mathrm{Y}$ ya que está en sintonía, puede exponerse por qué cierta vertiente de las posibles merece preferencia. ¿Cuál? La que el

13 Para abundar, véase Thomas S. Kuhn (1996).

14 Como lo denomina Milton Friedman.

15 Para quienes encuentran estímulo en pensar y entender. 
perito considera preferible. $Y$ cuando es preguntado sobre las alternativas, debe ${ }^{16}$ indicar todas las (válidamente ${ }^{17}$ ) disponibles $\mathrm{y}$, de entre ellas, por qué una merece preferencia.

No faltará quien cuestione lo anterior indicando contradicción: habiendo aseverado que el perito no debe abogar, lo anterior resuena mucho a ello. Contestaría que el perito no debe abogar por el cliente o su postura en el proceso, pero sí por la postura técnica que considera más apropiada. Es decir, defender su concepción de lo que es más técnico. Entendido así, defender es distinto a abogar.

\section{Comentario final}

El perito cumple una función importante cuando expone de una manera objetiva un tema técnico al árbitro, incluyendo su opinión sincera. En esta oración, el adjetivo es clave: "sincera". El perito debe ser franco con lo que piensa y por qué lo piensa. Y si hay un eslabón débil en su cadena expositiva, debe admitirlo si se le pregunta. Al hacerlo, no está mal que defienda, siempre que se ciña a su tema y lo haga en el plano de la honestidad intelectual - no como aun otro abogado del equipo legal de quien lo ofrece-. Este es y debe ser el prurito de todo perito.

\section{Referencias}

Kuhn, T. S. (1996). The structure of scientific revolutions. (3 ${ }^{\text {rd }}$ edition). Chicago: The University of Chicago Press.

Posner, R. A. (2013). Reflections on judging. Cambridge, Massachusetts: Harvard University Press.

Vargas Llosa, M. (2009). Sables y utopías. Lima: Aguilar.

16 El lector cuidadoso deseará saber por qué aludo a "deber". ¿Cuál es el fundamento? El cuestionamiento sería tan apropiado como exigente. Contestaría que el fundamento de la aseveración es honestidad intelectual. Lo que considero la forma correcta de discutir y buscar persuadir.

17 La validez de una postura dentro del margen de apreciación la dictarán las reglas de la ciencia en cuestión. 
